\title{
Knowledge and Beliefs Regarding TMD: Has Anything Changed After 20 Years?
}

\author{
Felipe B. Porto, ${ }^{1, *}$ Mark Litt, ${ }^{1}$ Miranda E. Jennings, ${ }^{2}$ Hisham Rifaey, ${ }^{3}$ and Susan Reisine ${ }^{1}$ \\ ${ }^{1}$ Department of Oral Health and Diagnostic Sciences, University of Connecticut, Farmington CT, United States of America \\ ${ }^{2}$ Northcentral University, Arizona, United States of America \\ 3 University of Connecticut, Farmington CT, United States of America \\ ${ }^{*}$ Corresponding author: Felipe B. Porto, Department of Oral Health and Diagnostic Sciences, University of Connecticut, Farmington CT, United States of America. Tel: $+860-$ \\ 6792778, Fax: +860-6791342, E-mail: felipebporto@hotmail.com
}

Received 2015 July 6; Revised 2015 October 28; Accepted 2015 November 15.

\begin{abstract}
Background:Due to the variety of factors involved in TMDs it is not surprising to see a wide range of treatment modalities being suggested for TMD patients. However, one determinant of treatment for TMD that is often overlooked is the practitioner's knowledge and beliefs about the syndrome itself.

Objectives: To evaluate changes in experts' knowledge and beliefs regarding Temporomandibular Disorders (TMD) since the administration of the first such survey by Le Resche, Truelove and Dworkin in 1993.

Patients and Methods: A survey invitation was emailed to 62 dentists and 19 psychologists, all determined to be experts in the orofacial pain/TMD field. All dentists selected to be part of this survey were members of the American Academy of Orofacial Pain. Psychologists were selected based on their publications in this field. The Le Resche et al. questionnaire was used with the following adaptations: four new statements were inserted; one statement was removed; and a 6-point Likert agreement scale for each statement was used instead of the original 11-point scale. Reminder emails were sent at one week and one month to maximize the response rate. Changes in responses to each item from the original survey were assessed using z-test.

Results: Thirty-four dentists but only three psychologists responded to the survey. Therefore only responses from dentists were used in the analysis. Overall there was a high level of agreement between the original sample and the current sample. Of the 34 original items there was very clear consensus on 24. There was consensus on two new items in the survey on the need for a tomogram and splint therapy. Conclusions: Twenty years after the original survey, the knowledge and beliefs regarding TMDs among experts in this field have not changed significantly.
\end{abstract}

Keywords: Temporomandibular Disorders, Orofacial Pain, Health Survey, Knowledge, Beliefs

\section{Background}

The American academy of orofacial pain (AAOP) defined temporomandibular disorder (TMD) as a "collective term that embraces a number of clinical problems that involve the masticatory muscles, the TMJ, and the associated structures" (1). As the definition states, TMD is not a single clinical entity, but a syndrome, and its etiology has been debated since the conditions were first described.(2-8) Due to the variety of factors involved in TMDs it is not surprising to see a wide range of treatment modalities being suggested for TMD patients (9-15). However, one determinant of treatment for TMD that is often overlooked is the practitioner's knowledge and beliefs about the syndrome itself (16-18).

In 1993, Le Resche, Truelove and Dworkin (17) evaluated knowledge and beliefs regarding TMD and its treatment among dentists using a survey. Two panels of experts were used to create the knowledge survey. The responses of these experts were used to determine the criterion response for each knowledge/belief item evaluated. Thirteen dentists who had extensively published about TMD composed one panel of experts. Their responses were used to determine criterion responses for items relating to the areas of psychophysiology, chronic pain and pathophysiology. The second panel of experts included fourteen psychologists who had experience in multidisciplinary chronic pain clinics. Their responses were used to determine criterion responses in the areas of chronic pain and psychiatric disorders. Le Resche et al. (17) mailed the survey to 247 general dentists and 212 specialists involved in seeing patients with TMD. Results of the survey indicated that among both general dentists and specialists of the time there was considerable variation in knowledge about the psychophysiological and pathophysiological aspects of TMD.

One reason for the large variation in knowledge about TMD, its etiology, and its treatment, is that orofacial pain is often not considered a dental specialty, and therefore many dental schools in the U.S. do not have a specific orofacial pain (and/or TMD) discipline. Instead, any teaching about orofacial pain is usually divided up among sev-

Copyright (C2016, Health Promotion Research Center. This is an open-access article distributed under the terms of the Creative Commons Attribution-NonCommercial 4.0 International License (http://creativecommons.org/licenses/by-nc/4.0/) which permits copy and redistribute the material just in noncommercial usages, provided the original work is properly cited. 
eral disciplines such as oral surgery, orthodontics, and prosthodontics (19). As an attempt to improve the knowledge about orofacial pain and TMD, pre-doctoral courses focused on orofacial pain have been discussed and recommended, but few are in place (20-22).

Given the fragmented nature of TMD/orofacial pain instruction in the dental community one question that presents itself is whether multiple providers, even those considered experts, can come to consensus about the etiology and treatment of TMD.

\section{Objectives}

The present survey aimed to evaluate experts' knowledge and beliefs regarding temporomandibular disorders (TMD), and to determine whether such knowledge has changed since the administration of the first such survey by Le Resche, Truelove and Dworkin (1993) (17). The results could guide the development of much needed unified curricula in TMD pain for dental students.

\section{Patients and Methods}

Institutional review Board approval was sought and obtained prior to the beginning of this study.

\subsection{Subjects}

The survey was administered to samples of experts in the area of TMD. Two distinct TMD expert groups were selected. One group was called Dentists-TMD experts and the second group was called Psychologists-TMD experts. The DentistsTMD experts' responses answered all domains of the survey. Experts were chosen by the investigators based on knowledge about the TMD field and publication history in TMD. A total of 62 academic dentists were selected, all of whom were involved with the management of orofacial pain patients and members of the American Academy of Orofacial Pain. Additionally, 19 psychologists involved in orofacial pain research and/or clinical management of orofacial pain patients were selected to participate in this study. No financial compensation was offered for participation.

\subsection{Measures}

TMD beliefs and knowledge were assessed using a 38item questionnaire adapted from a survey used by Le Resche et al. (17). As in the original survey, this questionnaire consisted of four domains: Pathophysiology (15 items), Chronic pain (10 items), Psychophysiology (9 items), and Psychiatric Disorders (4 items). On the original questionnaire used by Le Resche et al. (17), items were answered on a 11-point scale, from 0 -10, where 0 represented "strongly disagree”, 10 represented "strongly agree”, and 5 represented neutral. On the current questionnaire each item consisted of a statement to which respondents were asked to indicate their agreement on a 6-point scale, where 0 represented I don't know, 1 represented strongly disagree, 2 represented disagree, 3 represented neutral, 4 represented agree, and 5 represented strongly agree. The respondents had the option to skip any of the questions.

The statements on the pathophysiology domain were related to the interaction of physical and psychological factors in TMD etiology, diagnosis, and treatment. The chronic pain domain included questions regarding the causes, diagnosis, and appropriate treatment of chronic pain conditions, as applied to TMD. The psychophysiology domain contained questions about the biomedical or biomechanical aspects of TMD etiology, diagnosis, and treatment. Finally, the psychiatric disorders domain included questions related to anxiety, depression, and somatization associated with TMD. The Psychologists-TMD experts' survey excluded the pathophysiology domain.

Few changes were made to the original survey. On the Pathophysiology domain: the question "transcranial films are the most accurate method for viewing the TMJ joint," which was present on the original survey, was excluded on the current questionnaire since this technique is no longer used. Three new questions were inserted on the current survey:a) "panoramic film is a reasonable method to evaluate the bony structures of the TMJ;" b) "when bony changes are seen on a panoramic film, a tomogram is mandatory in order to define the treatment plan;" and c) "splint therapy is only effective when used more than 16 hours/day."

On the Chronic Pain domain the question "poor quality of sleep is a major factor in the development of TMD" was inserted on the current survey. If considered as an overall measure of beliefs and attitudes about TMD and its treatment, the 38 items do cohere as a scale, with an internal reliability of alpha $=0.65$.

\subsection{Procedures}

The Dentists and Psychologists-TMD experts were solicited via e-mail and requested to complete the survey online, via a secure link to an online survey program, Questionmark (Norwalk, CT), which itself operates on a secure system (SAS 70 Type II-certified data center). The e-mail explained that the purpose of the study was to evaluate current knowledge and beliefs about the treatment of TMD. It was stressed that the completion of the survey was entirely voluntary, and that responses would be anonymous. No personal identification was requested. Two reminder e-mails were sent; the first reminder was e-mailed one week after the initial solicitation, and the second reminder was sent after one month.

In the current study each respondent's score on each item was recoded to either Disagree (for scores of 1 or 2) or Agree (for scores of 4 or 5). For each item the number of agreements and disagreements over all respondents were tallied. A consensus was considered present when there was a significant difference by non-parametric binomial distribution test between agreements and disagreements. Percent of respondents agreeing or disagreeing with each item was then calculated.

In order to draw comparisons with responses from the Le Resche et al. survey, the percent agreement for each item among the experts in the Le Resche group was com- 
pared to the percent agreement for each item among the dental experts in the current survey group using a twoproportion z-test for each item (17).

\section{Results}

Thirty-four Dentists-TMD experts (response rate 54.8\%) and three Psychologists-TMD experts (response rate 15.7\%) completed the online questionnaire. Three of the 34 Dentists who answered the questionnaire did not answer all questions. The Psychologists' responses were not used because the response rate was so low. Tables 1 - 4 summarize the results of the current survey compared to those of the original survey. Of the 34 original items, levels of agreement between the original expert sample and the current sample were significantly different on 10 . In the pathophysiology domain the present sample was slightly more skeptical about the value of orthodontic treatment, and slightly more accepting or arthroscopic surgery, than was the original sample. Current experts were also slightly less accepting of icepacks and passive muscle stretching than were the earlier experts, and were less likely to commit to the idea that TMJ clicking did not always require treatment. In the chronic pain domain current experts were much less likely to disagree with the idea that TMJ patients should be advised to rest, and slightly less likely to dis- agree with the idea that previous treatment failures are an indication for surgery.

In the psychophysiology domain there were minor differences in levels of agreements regarding the mechanisms of acute and chronic pain and the role that stress and tension play in TMD pain. And in the psychiatric disorders domain current experts were less likely to disagree with the idea that depression is rare in TMJ patients. Despite the differences in levels of agreement noted here, however, the degree to which past and current respondents agreed with each other is striking.

Among all questions, four questions received more than 15 percent "neutral" responses: a) Chronic TMD patients should be advised to rest and limit their work and social activities when they are experiencing pain (neutral $=29 \%$ ); b) Panoramic film is a reasonable method to evaluate the bony structures of the TMJ (neutral = 21.2\%); c) Stress is a major factor in the development of TMD (neutral =19.3\%); and d) Poor quality of sleep is a major factor in the development of TMD (neutral $=16.1 \%$ ).

Among the four new questions, the questions regarding the panoramic film as being a reasonable method to evaluate the bony structures of the TMJ, and the question regarding the poor quality of sleep as being a major factor in the development of TMD presented no consensus (Table 5).

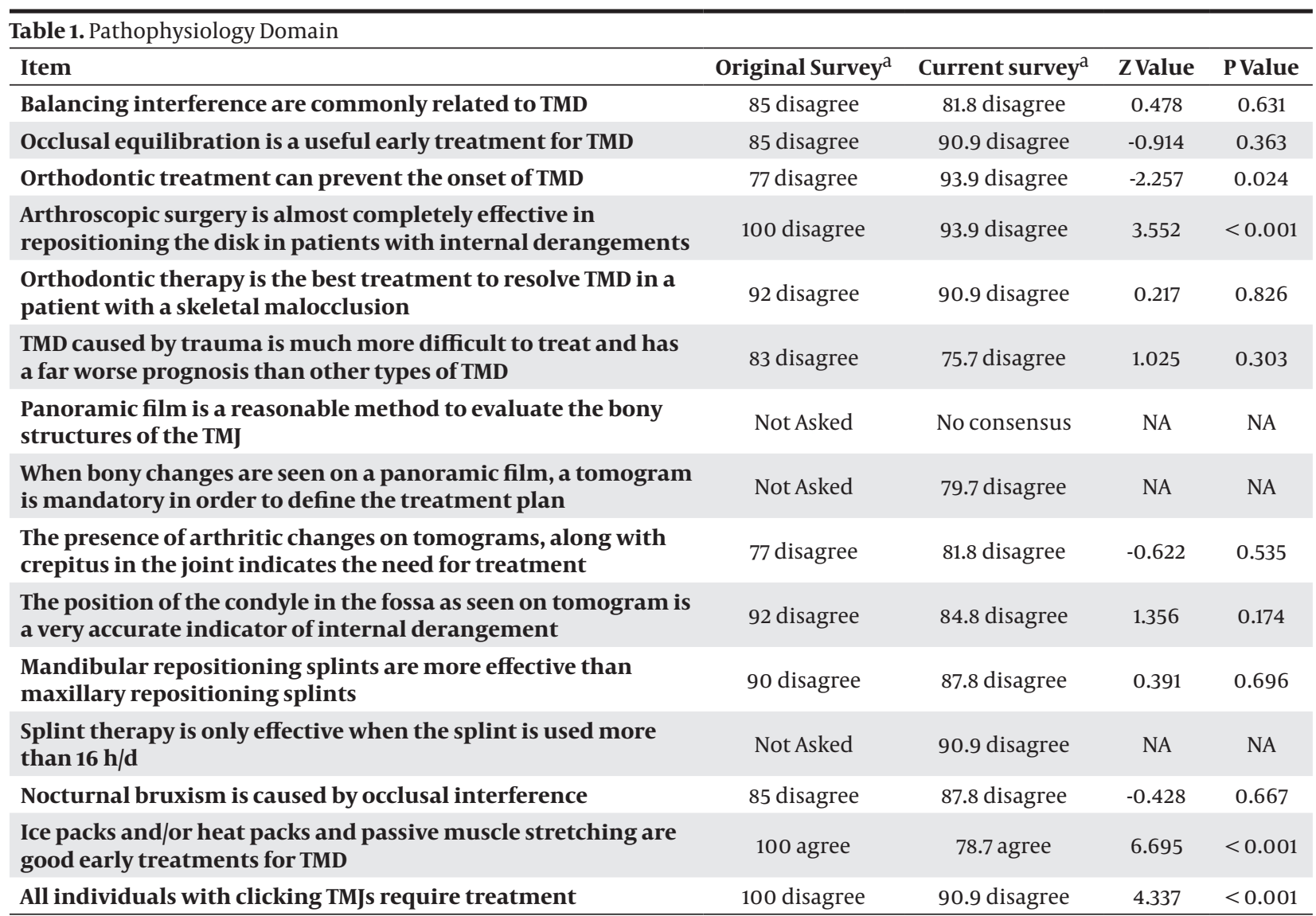

Abbreviation: NA, not available.

${ }^{a}$ Values are presented as No. (\%). 
Table 2. Chronic Pain Domain

\begin{tabular}{|c|c|c|c|c|}
\hline Item & Original Survey $^{\mathrm{a}}$ & Current Survey ${ }^{\mathrm{a}}$ & Z Value & P Value \\
\hline $\begin{array}{l}\text { Chronic TMD patients should be advised to rest and limit } \\
\text { their work and social activities when they are experiencing } \\
\text { pain }\end{array}$ & 86 disagree & 51.6 disagree & 4.742 & $<0.001$ \\
\hline $\begin{array}{l}\text { PRN narcotics ("as needed" for pain) are a treatment of } \\
\text { choice when TMD pain is severe }\end{array}$ & 93 disagree & 90.3 disagree & 0.557 & 0.575 \\
\hline $\begin{array}{l}\text { Antidepressants are never indicated in the management of } \\
\text { TMD }\end{array}$ & 88 disagree & 93.5 disagree & -0.941 & 0.347 \\
\hline $\begin{array}{l}\text { An extensive history of previous treatment failures in a TMD } \\
\text { patient is usually an indication for surgery }\end{array}$ & 100 disagree & 96.7 disagree & 2.601 & 0.009 \\
\hline Chronic pain is a behavioral, as well as a physical problem & 96 agree & 93.5 agree & 0.661 & 0.509 \\
\hline $\begin{array}{l}\text { Although some TMD patients have psychological problems, } \\
\text { these problems are usually unrelated to their pain }\end{array}$ & 85 disagree & 83.8 disagree & 0.181 & 0.857 \\
\hline $\begin{array}{l}\text { Poor quality of sleep is a major factor in the development of } \\
\text { TMD }\end{array}$ & Not Asked & No consensus & NA & NA \\
\hline Difficulty with sleep is a common finding in chronic pain & 96 agree & 96.7 agree & -0.195 & 0.841 \\
\hline $\begin{array}{l}\text { Some patients use pain as an excuse to avoid unpleasant } \\
\text { chores }\end{array}$ & 89 agree & 83.8 agree & 0.872 & 0.384 \\
\hline $\begin{array}{l}\text { Behavior modification treatments are appropriate for } \\
\text { patients with chronic TMD pain }\end{array}$ & 88 agree & 87.1 agree & 0.149 & 0.881 \\
\hline
\end{tabular}

Abbreviation: NA, not available.

${ }^{\mathrm{a}}$ Values are presented as No. (\%).

Table 3. Psychophysiology Domain

\begin{tabular}{|c|c|c|c|c|}
\hline Item & Original Survey $^{\mathrm{a}}$ & Current Survey $^{\mathrm{a}}$ & Z Value & PValue \\
\hline The mechanisms of acute and chronic pain are the same & 100 disagree & 96.7 disagree & 2.601 & 0.009 \\
\hline Biofeedback can be useful for treating TMD & 77 agree & 87 agree & -1.313 & 0.190 \\
\hline $\begin{array}{l}\text { Oral parafunction habits are often significant in the } \\
\text { development of TMD }\end{array}$ & 85 agree & 74.2 agree & 1.569 & 0.116 \\
\hline $\begin{array}{l}\text { Patients with TMD who clench/brux do so either during } \\
\text { the day or at night, but not both }\end{array}$ & 92 disagree & 90.3 disagree & 0.333 & 0.741 \\
\hline Stress management is indicated for many TMD patients & 100 agree & 90.3 agree & 4.480 & $<.001$ \\
\hline Stress is a major factor in the development of TMD & 85 agree & 74.1 agree & 1.583 & 0.114 \\
\hline $\begin{array}{l}\text { Tension and stress increase jaw muscle EMG levels in } \\
\text { susceptible patients }\end{array}$ & 100 agree & 61.2 agree & 9.154 & $<.001$ \\
\hline $\begin{array}{l}\text { Progressive muscle relaxation is not an effective } \\
\text { treatment for TMD }\end{array}$ & 82 disagree & 80.6 disagree & 0.196 & 0.841 \\
\hline $\begin{array}{l}\text { Information on the daily pattern of the TMD symptoms } \\
\text { can be helpful for identifying contributing factors }\end{array}$ & 92 agree & 90.3 agree & 0.334 & 0.741 \\
\hline
\end{tabular}

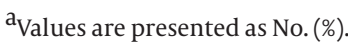


Porto FB et al.

\begin{tabular}{|c|c|c|c|c|}
\hline Item & Original Survey $^{\mathrm{a}}$ & Current Survey $^{\mathrm{a}}$ & Z Value & P Value \\
\hline Clinical depression is rare in chronic TMD patients & 100 disagree & 80.6 disagree & 6.373 & $<.001$ \\
\hline $\begin{array}{l}\text { Depressed mood is fairly common in chronic TMD } \\
\text { patients }\end{array}$ & 86 agree & 93.5 agree & -1.157 & 0.246 \\
\hline $\begin{array}{l}\text { Anxiety disorders are more common in TMD patients } \\
\text { than in the population at large }\end{array}$ & 79 agree & 74.2 agree & 0.605 & 0.549 \\
\hline $\begin{array}{l}\text { Depression can be an important etiologic factor in } \\
\text { chronic pain }\end{array}$ & 79 agree & 74.1 agree & 0.630 & 0.528 \\
\hline
\end{tabular}

${ }^{a}$ Values are presented as No. (\%).

Table 5. Analysis of Questions not Presented on the Original Questionnaire, Results of Non-Parametric Tests of Binomial Distribution, Departure or Responses from $50 \%{ }^{\mathrm{a}}$

\begin{tabular}{|c|c|c|c|c|c|}
\hline Item & $\mathbf{N}$ & $\begin{array}{c}\text { Agree }+ \text { Strongly } \\
\text { Agree }^{b}\end{array}$ & Neutral $^{b}$ & $\begin{array}{l}\text { Disagree }+ \text { Strongly } \\
\text { Disagree }^{\mathrm{b}}\end{array}$ & P Value \\
\hline $\begin{array}{l}\text { Panoramic film is a reasonable method to evaluate the } \\
\text { bony structures of the TMJ }\end{array}$ & 31 & 42.4 & 21.2 & 30.3 & 0.541 \\
\hline $\begin{array}{l}\text { When bony changes are seen on a panoramic film, } \\
\text { a tomogram is mandatory in order to define the } \\
\text { treatment plan }\end{array}$ & 33 & 6 & 12.1 & 79.7 & $<.001$ \\
\hline $\begin{array}{l}\text { Splint therapy is only effective when the splint is used } \\
\text { more than } 16 \mathrm{~h} / \mathrm{d}\end{array}$ & 33 & 3 & 0 & 90.1 & $<.001$ \\
\hline $\begin{array}{l}\text { Poor quality of sleep is a major factor in the } \\
\text { development of TMD }\end{array}$ & 31 & 54.8 & 16.1 & 25.8 & 0.108 \\
\hline
\end{tabular}

${ }^{\mathrm{a}}$ Comparing the disagree column with the agree column.

balues are presented as No.(\%).

\section{Discussion}

The purpose of this paper was to update the findings of Le Resche et al. (1993) (17) about consensus on the etiology and management of TMDs among experts in this field. It is heartening that, despite the different backgrounds and philosophies of the experts surveyed here, there was largely consensus among this group about key aspects of TMD etiology, diagnosis and treatment. Furthermore, there was little change in consensus on most items from that reported by the original experts surveyed by Le Resche et al. (17).

Some differences were noted. On the current survey 93.9\% of the respondents disagreed with the statement "Orthodontic treatment can prevent the onset of TMD", against $77 \%$ of the respondents in the original survey. This topic has been extensively investigated, and despite the fact most of the publications support that Orthodontic treatment is not able to prevent TMD (23-27), some papers support the opposite $(28,29)$. Most of the papers that stated that orthodontic treatment does not prevent TMD were published after 1990, and this might explain why the current survey shows a higher percentage of respondents who disagreed with the above-mentioned statement.

The two items related with surgical approach in TMD reached consensus on the original and current surveys. However, on the current survey, for both items the percentages of consensus were significantly different from the original survey. On the current survey 93.9\% disagreed with the statement "arthroscopic surgery is almost completely effective in repositioning the disk in patients with internal derangements", and 96.7\% disagreed with the statement "an extensive history of previous treatment failures in a TMD patient is usually an indication for surgery" while on the original survey $100 \%$ of the respondents among the group of experts disagreed with both statements. The literature regarding arthroscopic surgery success in repositioning disk (30-33), and regarding the indication for surgery in TMD patients $(33,34)$ is not conclusive.

The statement "Tension and stress increase jaw muscle EMG levels in susceptible patients" that $100 \%$ of the respondents agreed with in the original survey was endorsed by only $61.2 \%$ in the current survey. Several studies have investigated the relationship between stress and jaw muscle activity (35-38), and concluded that there is an increase of the masticatory muscles EMG levels when exposed to mental stress. Therefore, the responses on the original survey seemed to more accurately reflect the state of the science than the current survey's responses. It was surprising that 19 percent of the experts could neither agree nor disagree with this statement. It is possible that the neutral responses on this item stemmed from the use of the word "major," indicating some remaining 
skepticism among some dentists regarding the significance of the role of stress in development of TMDs. Two other statements on the psychophysiologic domain presented statistically significant differences between the two surveys. While on the original survey $100 \%$ disagreed with the statement "the mechanism of acute and chronic pain are the same", on the current survey $96.7 \%$ opposed the same statement. The literature seems to agree that the mechanism involved in chronic pain present similarities and differences from the one in acute pain $(39,40)$; but the fact that the first is a consequence of the second, may explain why some respondents did not disagree with this specific statement. The other statement presenting significant difference from to the original survey to the current one is "stress management is indicated for many TMD patients". The use of stress management for patients with TMD has been proved to be an excellent treatment approach $(41,42)$; it is surprising that there was a decrease in agreement with this statement on the current survey when comparing to the original survey.

Several items received more than 15 percent of neutral responses. The statement with the highest neutral response was: "Chronic TMD patients should be advised to rest and limit their work and social activities when they are experiencing pain" (neutral $=29 \%$ ). It is possible that on the current survey the dentists, who responded neutral, felt that this question is not related to their area of expertise. On the original survey the Psychologists' responses were used as the "expert response" for this same question.

The item, "poor quality of sleep is a major factor in the development of TMD," also received a score of neutral in more than 15 percent of cases (16.1\%). Again, the relationship between pain and sleep quality in TMD patients is well documented, (43-47) but whether poor sleep is a cause or a result of TMD may have given some respondents pause.

Among the items added to the survey, one showed greater than 15 percent of neutral responses; it was related to the use of panoramic films when evaluating the TMDs. In fact, one of the two items related to this topic elicited no agreement among the experts (Table 5). The studies regarding the utility of panoramic radiographs for diagnosis or screening of TMD are mixed (48-50), and the lack of agreement among the respondents reflects these mixed findings.

A major shortcoming of the paper was the poor response rate among psychologists (15\%), limiting the study only to dentists whose response rate was more acceptable at $54.8 \%$. The authors acknowledge that the response rate being slightly over fifty four percent is also low, but it is important to consider that the current survey had 34 responses from TMD experts while the original survey used the responses from 13 TMD experts.

The current survey indicates that, despite the fragmented nature of education in the area of TMD/orofacial pain, and the different practices and philosophies of the many kinds of practitioners involved with these disorders, great consensus exists among experts about the nature and treatment of TMD/orofacial pain. Thus surveys like the one used here may provide good tests of knowledge for those studying these disorders.

Additionally, it was seen that, despite the proliferation of research and new publications about TMD, knowledge and beliefs regarding this topic have not significantly changed in the past 20 years. Further research will be needed to expand this knowledge base, and provide a common set of topics for effectively educating students in best practices for treatment of TMD/orofacial pain.

\section{Footnote}

Authors' Contribution:Study concept and design: Felipe B. Porto and Miranda E. Jennings; analysis and interpretation of data: Felipe B. Porto and Mark Litt; drafting of the manuscript: Felipe B. Porto, Hisham Rifaey, Mark Litt and Susan Reisine; critical revision of the manuscript for important intellectual content: all authors; statistical analysis, Felipe B. Porto and Mark Litt.

\section{References}

1. Orofacial pain: Guidelines for assessment, diagnosis, and management. 4th ed. Chicago, IL: Quintessence books; 2008.

2. Sicher H. Some aspects of the anatomy and pathology of the temporomandibular articulation. N Y State Dent J. 1948;14(8):451-69. [PubMed: 18884516]

3. Sicher H. Temporomandibular articulation in mandibular overclosure. J Am Dent Assoc. 1948;36(2):131-9. [PubMed:18906440]

4. Costen JB. A syndrome of ear and sinus symptoms dependent upon disturbed function of the temporomandibular joint 1934. Ann Otol Rhinol Laryngol. 1997;106(10 Pt 1):805-19. [PubMed: 9342976]

5. Hall RE. Movements of the mandible and approximate mechanical imitation of these movements for the arrangement and grinding of artificial teeth for the efficient restoration of lost masticatory function in edentulous cases. J NATL DENT ASSOC 1920;7(8):677-86

6. Wright WH. Deafness as influenced by malposition of the jaws. J Nat Dent Assoc. 1920;7(12):979-92. doi: 10.14219/jada.archive.1920.0182.

7. Monson GS. Occlusion as applied to crown and bridge-work. J Nat Dent Assoc.1920;7(5):399-413. doi:10.14219/jada.archive.1920.0071

8. Prentiss HJ.A preliminary report upon the temporomandibular articulation in the human type. Dent Cosmos. 1918;60:505-12.

9. Yatani H, Minakuchi H, Matsuka Y, Fujisawa T, Yamashita A. The long-term effect of occlusal therapy on self-administered treatment outcomes of TMD. J Orofac Pain. 1998;12(1):75-88. [PubMed: 9656902]

10. Polso HL, Napankangas R, Raustia AM. Treatment outcome in patients with TMD--a survey of 123 patients referred to specialist care. Cranio. 2010;28(3):156-65. doi: 10.1179/crn.2010.022. [PubMed: 20806733]

11. Litt MD, Shafer DM, Kreutzer DL. Brief cognitive-behavioral treatment for TMD pain: Long-term outcomes and moderators of treatment. Pain. 2010;151(1):110-6. doi:10.1016/j.pain.2010.06.030. [PubMed: 20655662]

12. Littner D, Perlman-Emodi A, Vinocuor E. [Efficacy of treatment with hard and soft occlusal appliance in TMD]. Refuat Hapeh Vehashinayim (1993). 2004;21(3):52-8. [PubMed: 15503982]

13. Miller DB. Invisalign in TMD treatment. Int J Orthod Milwaukee. 2009;20(3):15-9. [PubMed:19835182]

14. Tecco S, Tete S, Crincoli V, Festa MA, Festa F. Fixed orthodontic therapy in temporomandibular disorder (TMD) treatment: an alternative to intraoral splint. Cranio. 2010;28(1):30-42. doi:10.1179| 
Porto FB et al.

crn.2010.005. [PubMed:20158007]

15. Stack BC. Intraoral orthotics for treatment of TMD. Funct Orthod. 2004;21(2):16-22. [PubMed: 15453014]

16. Glaros AG, Glass EG, McLaughlin L. Knowledge and beliefs of dentists regarding temporomandibular disorders and chronic pain. J Orofac Pain. 1994;8(2):216-22. [PubMed:7920357]

17. Le Resche L, Truelove EL, Dworkin SF. Temporomandibular disorders: A survey of dentists' knowledge and beliefs. J Am Dent Assoc. 1993;124(5):90-4. [PubMed: 8482787]

18. Lee WY, Choi JW, Lee JW. A study of dentists' knowledge and beliefs regarding temporomandibular disorders in Korea. Cranio. 2000;18(2):142-6. [PubMed: 11202825]

19. Klasser GD, Greene CS. Predoctoral teaching of temporomandibular disorders: a survey of U.S. and Canadian dental schools. J Am Dent Assoc. 2007;138(2):231-7. [PubMed: 17272380]

20. Fricton JR. Development of orofacial pain programs in dental schools. J Orofac Pain. 2002;16(3):191-7. [PubMed:12221735]

21. Greene CS, Stockstill JW, Clark GT. Predoctoral education for TMD and orofacial pain: a philosophical overview. J Craniomandib Disord.1992;6(2):111-2. [PubMed:1401125]

22. Solberg WK, Fricton JR. The role of the dental school in teaching TMD and orofacial pain. J Craniomandib Disord. 1992;6(2):107-10. [PubMed:1401124]

23. Macfarlane TV, Kenealy P, Kingdon HA, Mohlin BO, Pilley JR, Richmond S, et al. Twenty-year cohort study of health gain from orthodontic treatment: temporomandibular disorders. Am J Orthod Dentofacial Orthop. 2009;135(6):692 e1-8. doi: 10.1016/j. ajodo.2008.10.017. [PubMed: 19524817]

24. McNamara Jr JA, Turp JC. Orthodontic treatment and temporomandibular disorders: is there a relationship? Part 1: Clinical studies. J Orofac Orthop. 1997;58(2):74-89. [PubMed: 9114557]

25. McNamara Jr JA, Seligman DA, Okeson JP. Occlusion, Orthodontic treatment, and temporomandibular disorders: A review. J Orofac Pain. 1995;9(1):73-90. [PubMed:7581209]

26. Spalj S, Slaj M, Athanasiou AE, Zak I, Simunovic M, Slaj M. Temporomandibular disorders and orthodontic treatment need in orthodontically untreated children and adolescents. Coll Antropol. 2015;39(1):151-8. [PubMed:26040083]

27. Mohlin BO, Derweduwen K, Pilley R, Kingdon A, Shaw WC, Kenealy P.Malocclusion and temporomandibular disorder:Acomparison of adolescents with moderate to severe dysfunction with those without signs and symptoms of temporomandibular disorder and their further development to 30 years of age. Angle Orthod. 2004;74(3):319-27. doi: 10.1043/0003-3219(2004)074<0319:MATDCO>2.0.CO;2. [PubMed: 15264641]

28. Michelotti A, Iodice G. The role of orthodontics in temporomandibular disorders. J Oral Rehabil. 2010;37(6):411-29. doi: 10.1111/j.1365-2842.2010.02087.x. [PubMed: 20406353]

29. Loft GH, Reynolds JM, Zwemer JD, Thompson WO, Dushku J. The occurrence of craniomandibular symptoms in healthy young adults with and without prior orthodontic treatment. Am J Orthod Dentofacial Orthop.1989;96(3):264-5. [PubMed:2773872]

30. Silva PA, Lopes MT, Freire FS. A prospective study of 138 arthroscopies of the temporomandibular joint. Braz J Otorhinolaryngol. 2015;81(4):352-7.doi:10.1016/j.bjorl.2014.08.021.[PubMed:26163228]

31. Abboud W, Yahalom R, Givol N. Treatment of Intermittent Locking of the Jaw in Wilkes Stage II Derangement by Arthroscopic Lysis and Lavage. J Oral Maxillofac Surg. 2015;73(8):1466-72. doi: 10.1016/j.joms.2015.02.027. [PubMed: 25970513]

32. Dimitroulis G. Outcomes of temporomandibular joint arthroscopy in patients with painful but otherwise normal joints. J Craniomaxillofac Surg. 2015;43(6):940-3. doi: 10.1016/j. jcms.2015.03.035. [PubMed:25951803]

33. Al-Moraissi EA. Open versus arthroscopic surgery for the management of internal derangement of the temporomandibular joint: A meta-analysis of the literature. Int J Oral Maxillofac Surg. 2015;44(6):763-70. doi: 10.1016/j.ijom.2015.01.024. [PubMed:
25701306]

34. Vos LM, Huddleston Slater JJ, Stegenga B. Arthrocentesis as initial treatment for temporomandibular joint arthropathy: a randomized controlled trial. J Craniomaxillofac Surg. 2014;42(5):e134-9. doi:10.1016/j.jcms.2013.07.010. [PubMed: 23994055]

35. Curran SL, Carlson CR, Okeson JP. Emotional and physiologic responses to laboratory challenges: patients with temporomandibular disorders versus matched control subjects.J Orofac Pain. 1996;10(2):141-50. [PubMed: 9133858]

36. Hidaka O, Yanagi M, Takada K. Mental stress-induced physiological changes in the human masseter muscle. J Dent Res. 2004;83(3):227-31. [PubMed:14981124]

37. Tsai CM, Chou SL, Gale EN, McCall WD. Human masticatory muscle activity and jaw position under experimental stress. J Oral Rehabil. 2002;29(1):44-51. [PubMed: 11844031]

38. Bakke M, Tuxen A, Thomsen CE, Bardow A, Alkjaer T, Jensen BR. Salivary cortisol level, salivary flow rate, and masticatory muscle activity in response to acute mental stress: A comparison between aged and young women. Gerontology. 2004;50(6):383-92. doi:10.1159/000080176. [PubMed:15477699]

39. Voscopoulos C, Lema M. When does acute pain become chronic? Br J Anaesth. 2010;105 Suppl 1:i69-85. doi: 10.1093/bja/aeq323. [PubMed: 21148657]

40. Hasenbring M, Hallner D, Klasen B. [Psychological mechanisms in the transition from acute to chronic pain: Over- or underrated?]. Schmerz. 2001;15(6):442-7. doi: 10.1007/s004820100030. [PubMed: 11793149]

41. Maisa Soares G, Rizzatti-Barbosa CM. Chronicity factors of temporomandibular disorders: A critical review of the literature. Braz Oral Res. 2015;29. doi: 10.1590/1807-3107BOR-2015.vol29.0018. [PubMed: 25590505]

42. Lopez C, Antoni M, Penedo F, Weiss D, Cruess S, Segotas MC, et al. A pilot study of cognitive behavioral stress management effects on stress, quality of life, and symptoms in persons with chronic fatigue syndrome. J Psychosom Res. 2011;70(4):328-34. doi: 10.1016/j. jpsychores.2010.11.010. [PubMed: 21414452]

43. Roehrs T, Hyde M, Blaisdell B, Greenwald M, Roth T. Sleep loss and REM sleep loss are hyperalgesic. Sleep. 2006;29(2):145-51. [PubMed:16494081]

44. Okifuji A, Hare BD. Do sleep disorders contribute to pain sensitivity? Curr Rheumatol Rep. 2011;13(6):528-34. doi:10.1007/s11926-0110204-8. [PubMed: 21805110]

45. Buxton OM, Hopcia K, Sembajwe G, Porter JH, Dennerlein JT, Kenwood C, et al. Relationship of sleep deficiency to perceived pain and functional limitations in hospital patient care workers. J Occup Environ Med. 2012;54(7):851-8. doi: 10.1097| JOM.ob013e31824e6913. [PubMed: 22796931]

46. Lentz MJ, Landis CA, Rothermel J, Shaver JL. Effects of selective slow wave sleep disruption on musculoskeletal pain and fatigue in middle aged women. J Rheumatol. 1999;26(7):1586-92. [PubMed:10405949]

47. Affleck G, Urrows S, Tennen H, Higgins P, Abeles M. Sequential daily relations of sleep, pain intensity, and attention to pain among women with fibromyalgia. Pain. 1996;68(2-3):363-8. [PubMed: 9121825]

48. Kambylafkas P,MurdockE, Gilda E, Tallents RH, Kyrkanides S. Validity of panoramic radiographs for measuring mandibular asymmetry. Angle Orthod. 2006;76(3):388-93. doi: 10.1043/0003-3219 (2006)076[0388:VOPRFM]2.0.CO;2. [PubMed:16637716]

49. Lewis EL, Dolwick MF, Abramowicz S, Reeder SL. Contemporary imaging of the temporomandibular joint. Dent Clin North Am. 2008;52(4):875-90. doi: 10.1016/j.cden.2008.06.001. [PubMed: 18805233]

50. Petersson A. What you can and cannot see in TMJ imaging-an overview related to the RDC/TMD diagnostic system.JOral Rehabil. 2010;37(10):771-8. doi: 10.1111/j.1365-2842.2010.02108.x. [PubMed: 20492436] 